\title{
BLENDS OF POLY(N-VINYL-2-PYRROLIDONE) AND DIHYDRIC PHENOLS: THERMAL AND INFRARED SPECTROSCOPIC STUDIES. PART IV
}

\author{
NICOLÁS GATICA*, LESLIE SOTO, CONSTANZA MORAGA AND LORETO VERGARA \\ Departamento de Polímeros, Facultad de Ciencias Químicas, Universidad de Concepción, Casilla 160-C, Concepción, Chile \\ (Received: July 29, 2013 - Accepted: October 9, 2013)
}

\begin{abstract}
The blending behaviour of binary systems formed by the polymer component poly(N-vinyl-2-pyrrolidone) (PVP) and the low molecular weight compounds 4,4'-biphenol (44BP) and 2,2'-biphenol (22BP) was studied. The blends were characterized in the entire composition range by Differential Scanning Calorimetry (DSC), Fourier Transform Infrared Spectroscopy (FTIR), Thermogravimetric Analysis (TGA), and Scanning Electron Microscopy (SEM). Both, the glass transition temperature (Tg) and the melting point (Tm) of the pure components were affected as a consequence of the blending process. It was observed miscibility between the components in both blends and a higher interaction degree in the blend containing 44BP. FTIR analysis detected the hydrogen bonding as intermolecular interaction responsible of the observed miscibility, by means of the variation in the wave number corresponding to the stretching vibration of PVP carbonyl group. TGA and SEM analyses provided coherent and complementary results with both DSC and FTIR.
\end{abstract}

Keywords: Polymer blends, poly (N-vinyl-2-pyrrolidone), 4,4'-biphenol, 2,2'-biphenol, hydrogen bond, low molecular weight compounds.

\section{INTRODUCTION}

In the artificial and synthetic polymers field, particular attention has been put to study their properties besides to improve them. Market requirements have promoted the interest to find materials with new applications, better utility levels, lower production costs and better processing technologies. Thus, the obtaining of copolymer materials and polymer blends has been progressively stimulated ${ }^{1-3}$. The combination of polymeric materials is not a new idea. In fact, some decades ago, one experiments with this kind of systems $^{2-7}$. When two or more polymer components are blended, the goal is to maintain or to improve the properties of the pure polymers ${ }^{1,8}$. A series of different materials can be obtained modifying one of the components or blend them in different proportions. Thus, each new material obtained will present unique and distinguishable properties. In this context, the miscibility is a very important subject to take into account. It is promoted by the existence of specific intermolecular interactions such as dipole-dipole intermolecular forces and hydrogen bonding ${ }^{8-12}$, which contribute to improve the molecular affinity degree between the components. Consequently the thermodynamic behavior of these blends corresponds to monophase systems.

At present, the study turns out to be interesting not only of blends containing polymers, but also of blends formed by a polymer and a low molecular weight compound (LMWC), which can improve notably the properties of the molecular component. This kind of blends turns out to be attractive not only from the fundamental point of view but also in the environmental area. It is possible to use polymeric materials in new applications that allow their recycling ${ }^{13}$.

In the area of the applied chemistry, a considerable number of LMWCs are included as additives to industrial formulations in order to improve the properties of macromolecular compounds, for instance: improvement of the properties of the rubber by carbon black ${ }^{14}$, protection during drying and storage of polyunsaturated elastomers by butylated hydroxytoluene ${ }^{15}$, improvement of mechanical properties of polyesters by triethanolamine ${ }^{16}$ and control of the conductivity of poly(butylene succinate)/polylactide blend ${ }^{17}$.

In the area of the pure chemistry, an increasing number of binary systems polymer-LMWC has been reported in the last decade. They have tried to describe the phenomenon of miscibility between the components from the molecular point of view, as a contribution to the best understanding of the features and mechanism that govern the blending process: thermodynamic quality of hydrocarbons for styrene-butadiene-styrene triblock copolymer ${ }^{18}$, crystallization of the blend poly(2-vinyl pyridine)-block-poly(e-caprolactone) pentadecylphenol ${ }^{19}$, $\mathrm{PEO} /$ fatty acid blends for thermal energy storage materials ${ }^{20}$, phase change materials based on low density polyethylene/paraffin wax blends ${ }^{21}$, poly(acrylamide-co-itaconic acid) as a potential ion-exchange sorbent for effective removal of antibiotic drug-ciprofloxacin ${ }^{22}$, etc.

In any case, the obtaining of miscible blends is the result of specific interactions between the components. For this, a series of functionalized polymers has been used and reported by different authors $8,12,23-25$ as well as by the authors of this work ${ }^{26-28}$. Poly(N-vinyl-2-pyrrolidone) is a water soluble functionalized vinyl polymer, physiologically compatible, non-toxic, and colorless $^{29}$. Its monomer unit, N-vinyl-2-pyrrolidone shows an amphiphilic nature as a consequence of its amide polar group, which provides hydrophilic character to the macromolecule, and of methine and methylene groups, which provide hydrophobic moieties ${ }^{30}$. This combination of properties predestined its use in numerous applications in medicine, pharmaceutical technology, cosmetics, in the technical industry, as stabilizer of suspensions, in ophthalmic preparations and in film coating ${ }^{29}$. On the other hand, a series of dihydroxy phenols has been used as blend components ${ }^{26-28,31-33}$ due to their molecular structure, which has promoted the obtaining of miscible blends with different functionalized polymers ${ }^{27}$.

This work presents a study of the miscibility behavior of blends formed by poly(N-vinyl-2-pyrrolidone) (PVP) as macromolecular component and 4,4'-biphenol (44BP) and 2,2'-biphenol (22BP) as LMWCs. The binary systems PVP/44BP and PVP/22BP were characterized by Differential Scanning Calorimetry (DSC), Fourier Transform Infrared Spectroscopy (FTIR), Thermogravimetric Analysis (TGA) and Scanning Electron Microscopy (SEM). The structural formulae of PVP; 44BP and 22BP are shown in Figure 1.

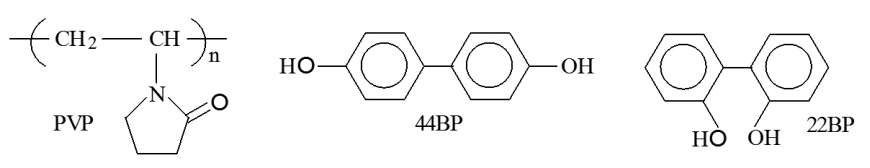

Figure 1. Structural formula of poly(N-vinyl-2-pyrrolidone) (PVP), 4,4'-biphenol (44BP), and 2,2'-biphenol (22BP).

\section{EXPERIMENTAL}

\section{Blend components}

Aldrich's PVP, 44BP (97\%) and 22BP (99 \%) were used. The weightaverage molecular weight $(\mathrm{Mw})$ and the glass transition temperature $(\mathrm{Tg})$ of PVP are $55,000 \mathrm{~g} / \mathrm{mol}$ and $161.0^{\circ} \mathrm{C}$ respectively. Melting points (Tm) of 44BP and 22BP were $281.8^{\circ} \mathrm{C}$ and $108.7^{\circ} \mathrm{C}$ respectively.

Preparation of blends

Blends of different compositions were obtained by solution casting using methanol as solvent. From these solutions, blends were prepared on Petri dishes with stirring of about $12 \mathrm{~h}$. After that, the solvent was evaporated at room temperature. Finally, the samples were dried under vacuum at room temperature for 2-3 weeks until constant weight. The blend concentration was about 2 weight $\%$.

Table 1 summarizes the compositions and the labels of the blends included in this work.

DSC measurements

The glass transition temperatures (Tg) of PVP and the blends, and the melting temperatures $(\mathrm{Tm})$ of 44BP, 22BP and the blends were obtained by Differential Scanning Calorimetry (DSC) using a differential scanning calorimeter TA Instruments Q200. Samples (3-4 mg) were placed inside 
aluminum pans and heated under flowing nitrogen $(50 \mathrm{~mL} / \mathrm{min})$, ranging from 0 to $300{ }^{\circ} \mathrm{C}$ for blend $\mathrm{C}$ and from 0 to $200{ }^{\circ} \mathrm{C}$ for blend $\mathrm{D}$, at $10\left({ }^{\circ} \mathrm{C} / \mathrm{min}\right)$ heating rate.

To minimize differences in the thermal history of the samples, the corresponding thermograms were obtained according to the following temperature program: heating up to $\mathrm{T}_{1}$ temperature (dynamic stage), isothermal stage at $T_{1}$ (static), cooling until the initial temperature (dynamic, quenching step), isothermal step at the initial temperature (static) and heating until the final temperature (dynamic) $\left[\mathrm{T}_{1}=200{ }^{\circ} \mathrm{C}\right.$ and $80^{\circ} \mathrm{C}$ for blends $\mathrm{C}$ and $\mathrm{D}$ respectively; final temperature $=300{ }^{\circ} \mathrm{C}$ and $200^{\circ} \mathrm{C}$ for blends $\mathrm{C}$ and D respectively]. In all cases, $\mathrm{Tg}, \mathrm{Tm}$ and the heat of fusion $\left(\Delta \mathrm{H}_{\text {fus }}\right)$ were evaluated from the last stage.

Samples were dried under reduced pressure in a vacuum oven prior to measurements.

\section{FTIR spectra}

Infrared spectra of PVP, LMWCs and their blends were recorded on a Nicolet Magna IR 550 Fourier transform infrared spectrophotometer. Spectra were recorded with a resolution of $1 \mathrm{~cm}^{-1}$. Samples were prepared directly in $\mathrm{KBr}$ pellets.

\section{TGA measurements}

Thermogravimetric measurements were performed using a thermo micro balance Netzsch TG 209 F1 Iris. Samples (about $5 \mathrm{mg}$ ) were placed inside aluminum pans and heated under flowing nitrogen $(20 \mathrm{~mL} / \mathrm{min})$ ranging from 30 to $600{ }^{\circ} \mathrm{C}$ at $10^{\circ} \mathrm{C} / \mathrm{min}$, obtaining the corresponding thermal decomposition profiles. Samples were dried under reduced pressure in a vacuum oven prior to measurements.

\section{SEM micrographs}

Blends were prepared according to the procedure described in the preparation of blends section. However, in this case a glass slide was deposited into the Petri dish, which was removed and kept at room temperature to allow the total solvent evaporation and the formation of an appropriate film for this technique. Dry sample was metalized by fixing of a carbon conducting band. Then, gold ions were deposited to allow the samples were conducting. Finally, the required magnifications were programmed by means of the microscope software and the images were obtained by means of a scanning electron microscope JEOL JSM $6380 \mathrm{LV}$.

Table 1. Composition and denomination of the studied blends.

\begin{tabular}{|c|c|c|}
\hline Blend & $\begin{array}{c}\text { Composition } \\
\text { (weight \% in LMWC) }\end{array}$ & Correlative denomination \\
\hline PVP + 44BP (C) & $\begin{array}{c}0,10,20,30,40,50, \\
60,70,80,90,100\end{array}$ & $\begin{array}{c}\text { 1C, 2C, 3C, 4C, 5C, 6C, } \\
\text { 7C, 8C, 9C, 10C, 11C }\end{array}$ \\
\hline PVP + 22BP (D) & $\begin{array}{c}0,10,20,30,40,50, \\
60,70,80,90,100\end{array}$ & $\begin{array}{c}\text { 1D, 2D, 3D, 4D, 5D, 6D, } \\
\text { 7D, 8D, 9D, 10D, 11D }\end{array}$ \\
\hline
\end{tabular}

\section{RESULTS AND DISCUSSION}

Analysis by Differential Scanning Calorimetry (DSC) allows the study of typical physical transitions of the components forming a polymer blend, such as the glass transition and the melting. Figure 2a shows the thermograms corresponding to the $1 \mathrm{C}-11 \mathrm{C}$ series obtained according to the procedure described in DSC measurements. It is possible to observe two kinds of signals: curves $8 \mathrm{C}-11 \mathrm{C}$, which show melting peaks corresponding to the melt of the LMWCs in the blends, and curves $1 \mathrm{C}-7 \mathrm{C}$, which present no peaks. A similar behavior was observed for blend D. As a consequence of the amount of energy involved, the melting peaks are bigger than the glass transition peaks and, consequently, it is not possible to observe the last ones in Figure 1-a. To evaluate the glass transition temperature $(\mathrm{Tg})$ it was necessary to analyze every thermogram separately, with the suitable heat flow scale. Figure $2 \mathrm{~b}$ presents the thermogram of the $5 \mathrm{C}$ sample, as a representative example; a signal centered in $137^{\circ} \mathrm{C}$ is observed for this case.

From the corresponding thermograms, the Tg values for PVP and its blends with 44BP and 22BP were obtained, which are collected in Table 2. Both in blend $\mathrm{C}$ and blend $\mathrm{D}$ a significant decreasing in the $\mathrm{Tg}$ of the polymer is observed as the content of 44BP (blend C) and 22BP (blend D) increases. This behavior, presented in Figure 3, is known as plasticizing effect and it has been observed in similar systems ${ }^{27,28}$. The addition of a plasticizer reduces the forces between the chains and increases the free volume between them. As a consequence, a lower amount of energy is necessary to produce the movement of the chain segments bringing about a Tg decreasing.
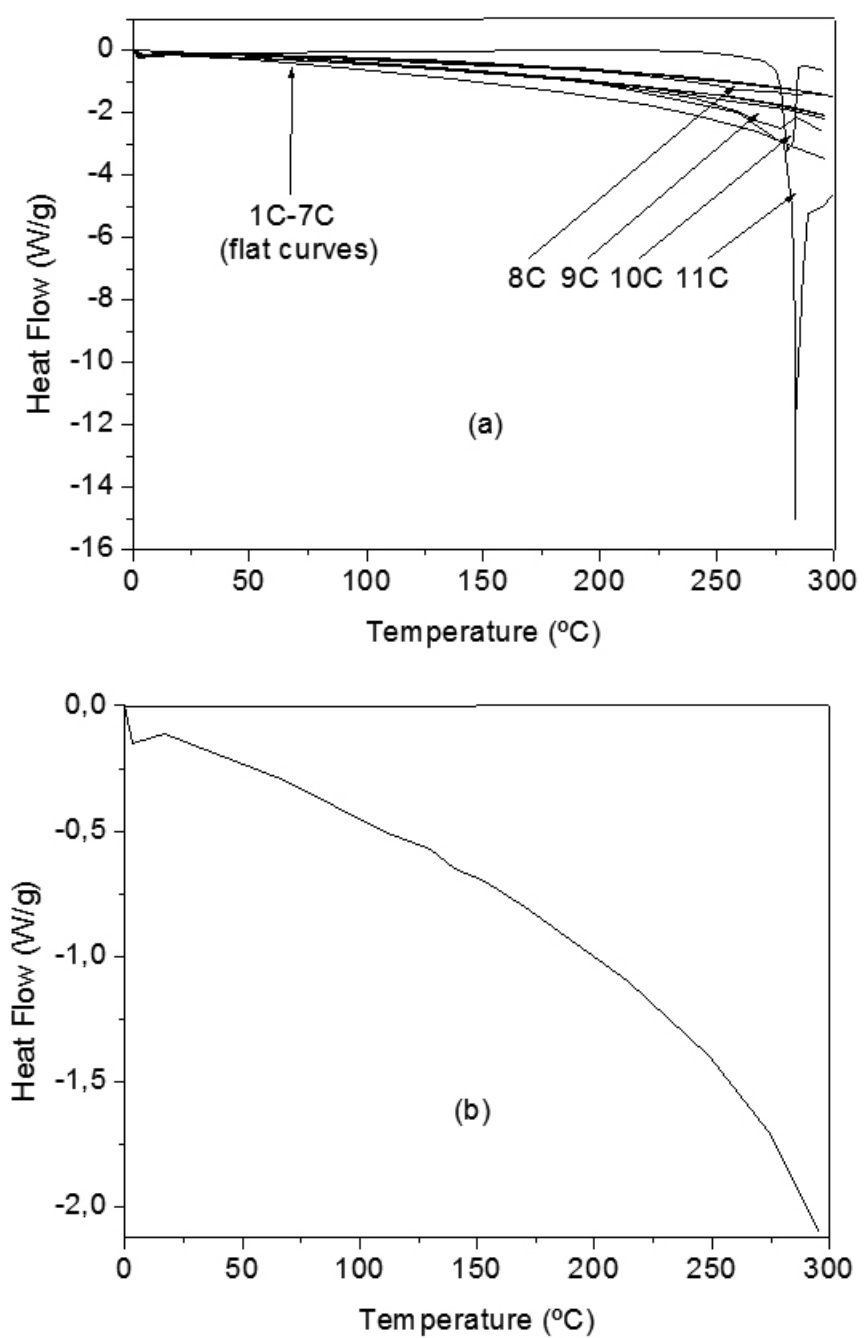

Figure 2. Thermograms of a) $1 \mathrm{C}-11 \mathrm{C}$ series and b) $5 \mathrm{C}$ sample (60 weight $\%$ PVP / 40 weight $\%$ 44BP).

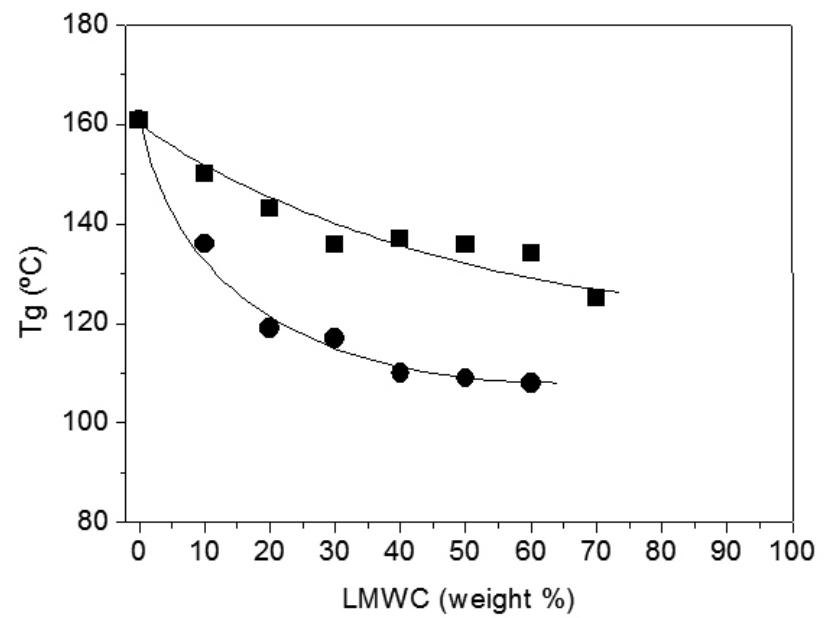

Figure 3. Glass transition temperature ( $\mathrm{Tg}$ ) variation with the composition for blends $\mathrm{C}(\mathbf{\square})$ and $\mathrm{D}(\mathbf{\bullet})$. 
Table 2. Glass transition temperature (Tg), melting temperature (Tm) and heat of fusion $(\Delta \mathrm{Hf})$ of blends $\mathrm{C}$ and $\mathrm{D}$.

\begin{tabular}{|c|c|c|c|c|c|c|}
\hline \multirow{2}{*}{$\begin{array}{c}\text { LMWC } \\
\text { (weight \%) }\end{array}$} & \multicolumn{3}{|c|}{ Blend C } & \multicolumn{3}{|c|}{ Blend D } \\
\hline & $\begin{array}{l}\mathrm{Tg} \\
\left({ }^{\circ} \mathrm{C}\right)\end{array}$ & $\begin{array}{l}\mathrm{Tm} \\
\left({ }^{\circ} \mathrm{C}\right)\end{array}$ & $\begin{array}{c}\Delta \mathrm{Hf} \\
(\mathrm{kJ} / \mathrm{mol})\end{array}$ & $\begin{array}{l}\mathrm{Tg} \\
\left({ }^{\circ} \mathrm{C}\right)\end{array}$ & $\begin{array}{l}\mathrm{Tm} \\
\left({ }^{\circ} \mathrm{C}\right)\end{array}$ & $\begin{array}{c}\Delta \mathrm{Hf} \\
(\mathrm{kJ} / \mathrm{mol})\end{array}$ \\
\hline 0 & 161 & - & - & 161 & - & - \\
\hline 10 & 150 & - & - & 136 & - & - \\
\hline 20 & 143 & - & - & 119 & - & - \\
\hline 30 & 136 & - & - & 117 & - & - \\
\hline 40 & 137 & - & - & 110 & - & - \\
\hline 50 & 136 & - & - & 109 & - & - \\
\hline 60 & 134 & - & - & 108 & - & - \\
\hline 70 & 125 & 267.0 & 4.5 & - & 107.4 & 7.6 \\
\hline 80 & - & 277.1 & 21.5 & - & 107.0 & 4.7 \\
\hline 90 & - & 280.1 & 30.4 & - & 108.6 & 13.1 \\
\hline 100 & - & 283.6 & 83.7 & - & 108.7 & 19.8 \\
\hline
\end{tabular}

By means of DSC the effect of the blending process on the fusion of the LMWCs was also studied. For that, the melting temperatures (Tm) of 44BP, 22BP and their blends were determined. These values are presented in Table 2 , which also collects the corresponding values of heat of fusion $(\Delta \mathrm{Hf}) .44 \mathrm{BP}$ has a higher Tm than 22BP`s Tm: $283.6^{\circ} \mathrm{C}$ and $108.7^{\circ} \mathrm{C}$ respectively. Melting point of 44BP reflects a bigger level of crystalline ordering in comparison with 22BP. This difference is a direct consequence of the relative position of the hydroxyl groups. In 44BP the larger and symmetrical spatial separation of these groups allows a larger degree of molecular ordering. The dependence of $\mathrm{Tm}$ with the composition reveals a decreasing of the melting temperature as the PVP content increases in the mixture: $283.6^{\circ} \mathrm{C}$ (pure 44BP; sample $11 \mathrm{C}$ ), $280.1{ }^{\circ} \mathrm{C}(10 \mathrm{C}), 277.1{ }^{\circ} \mathrm{C}(9 \mathrm{C})$, and $267.0^{\circ} \mathrm{C}(8 \mathrm{C})$. The melting peak disappears when the blend has a 40 weight $\%$ of PVP (sample $7 \mathrm{C}$ ). The corresponding heats of fusion $(\Delta \mathrm{Hf})$ were determined from the thermograms shown in Figure $2 \mathrm{a}$ by quantifying the area under the melting peaks. An evident decreasing in the same sense is observed: $83.7 \mathrm{~kJ} / \mathrm{mol}$ (sample 11C), $30.4 \mathrm{~kJ} / \mathrm{mol}(10 \mathrm{C})$, $21.5 \mathrm{~kJ} / \mathrm{mol}(9 \mathrm{C})$ and $4.5 \mathrm{~kJ} / \mathrm{mol}(8 \mathrm{C})$. This decreasing trend is consequence of the smaller energy amount required to produce fusion of 44BP as the PVP content increases in the blend. This fact reflects the loosing of crystallinity in 44BP with the increasing content of PVP up to reaching an amorphous state, in which the melting process is not present (composition 7C). A trend to decreasing of $\Delta \mathrm{Hf}$ with the increasing of the PVP content is also observed for blend D. However, such a trend is not as evident as in case of the blend C (Table 2). In addition, the melting temperature remains, in this case, practically constant. Differences observed by DSC allow postulating a larger interaction degree between the components of blend C (44BP and PVP).

As representative examples, Figure 4 shows FTIR spectra for blends 1D (100\% PVP / $0 \%$ 22BP), 3D (20 \% 22BP), 5D ( $40 \%$ 22BP), 7D (60 \% 22BP), $9 \mathrm{D}(80 \% 22 \mathrm{BP})$, and $11 \mathrm{D}(100 \%$ 22BP). The infrared radiation absorption due to the vibration of functional groups contained in the blend components, generates characteristic absorption bands that allow identify them. In the particular case of blends containing polymers, special attention should be put in the comparison of bands corresponding to pure components with regard to the blended components. Participation of a functional group in some kind of intermolecular interaction produces a change in its vibrational mode. Then, the band corresponding to the associated functional group turns out to be displaced with regard to the isolated group (pure component).

In this work, the absorption band corresponding to the stretching of the carbonyl function was studied. This group is present only in the polymer component. So, any change in the original value of wave number corresponds to a change in its molecular environment and can be attributed to an interaction between the blend components. Figure 5 shows the variation of the carbonyl group wave number with the blend composition; a displacement of this band placed at $1662 \mathrm{~cm}^{-1}$ is observed towards minor values as the blend becomes richer in LMWC. This wave number decreasing is associated to a minor energy amount to produce the stretching of the $\mathrm{C}=\mathrm{O}$ bond due to a part of the electronic density is involved in the intermolecular interaction with the LMWCs. Beside this, 44BP and 22BP contain hydrogen atoms bonded to electronegative oxygen atoms and therefore available for hydrogen bonding. Decreasing of the carbonyl wave number is suggesting that the main intermolecular interaction is hydrogen bonding between the blend components.

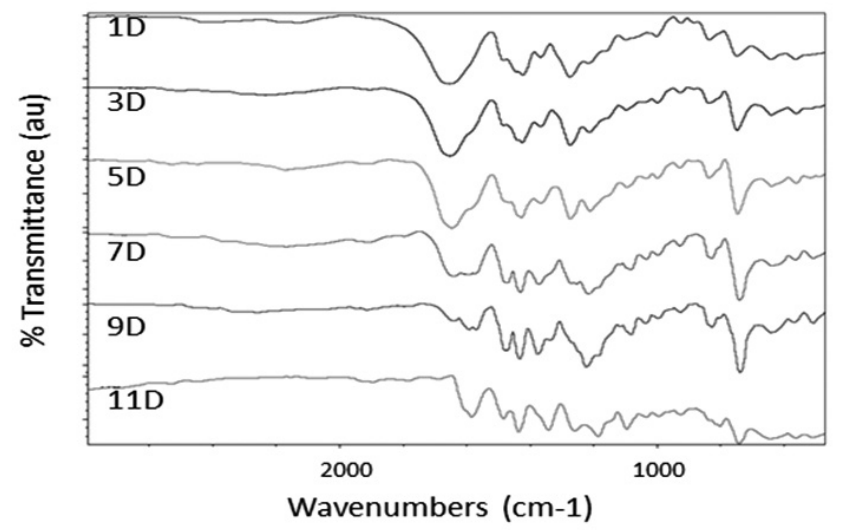

Figure 4. FTIR spectra for blends 1D, 3D, 5D, 7D, 9D, and 11D.

Thermogravimetrical Analysis was used as an additional analytical technique to characterize blends $\mathrm{C}$ and D. Figure 6 collects the thermal decomposition profiles for blend $\mathrm{D}$ as representative examples. They were obtained before DSC study and used to know the higher temperatures that can be applied to the samples without decomposition. As it was mentioned, the corresponding thermograms were obtained by DSC according to a temperature program that includes heating and cooling steps with the aim to minimize differences in the thermal history of the samples. $\mathrm{Tg}, \mathrm{Tm}$, and $\Delta \mathrm{H}_{\mathrm{fus}}$ were evaluated from the third stage (second heating stage) and therefore any thermal decomposition would prevent to obtain reliable results. Figure 6 shows a trend previously observed for similar polymer systems ${ }^{26-28}$ : intermediate decomposition curves are observed for the different blend composition and thermal decomposition profiles change progressively between the curves of the pure components. This behavior is also indicative of miscibility, as it has been observed for blends previously studied by the authors ${ }^{26-28}$. 


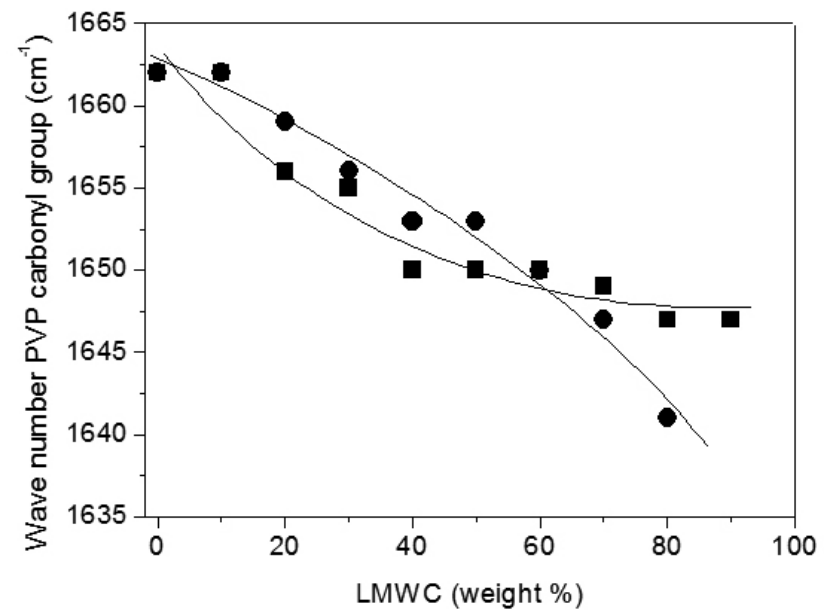

Figure 5. Wave number of PVP carbonyl group corresponding to the stretching vibration for blends $\mathrm{C}(\boldsymbol{\square})$ and $\mathrm{D}(\bullet)$.

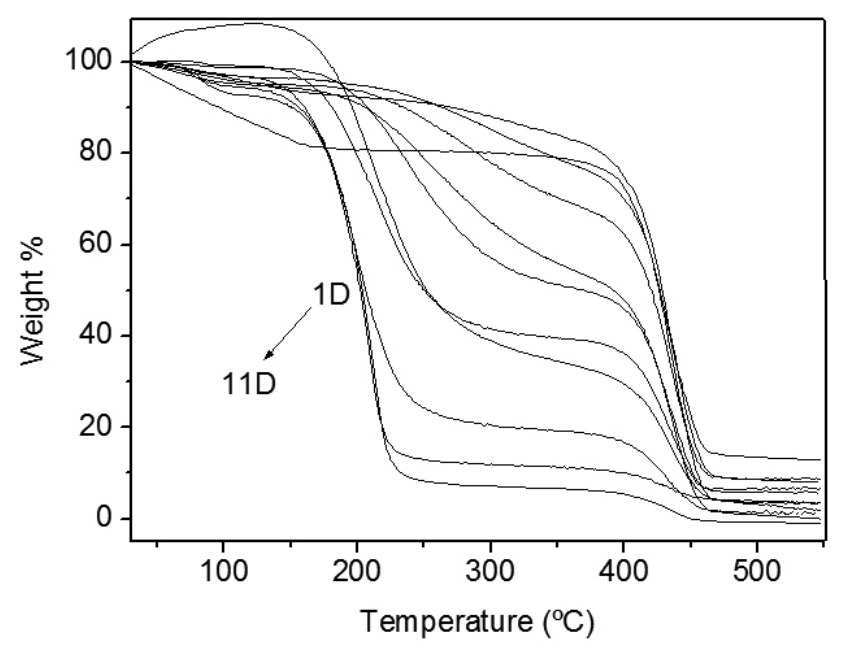

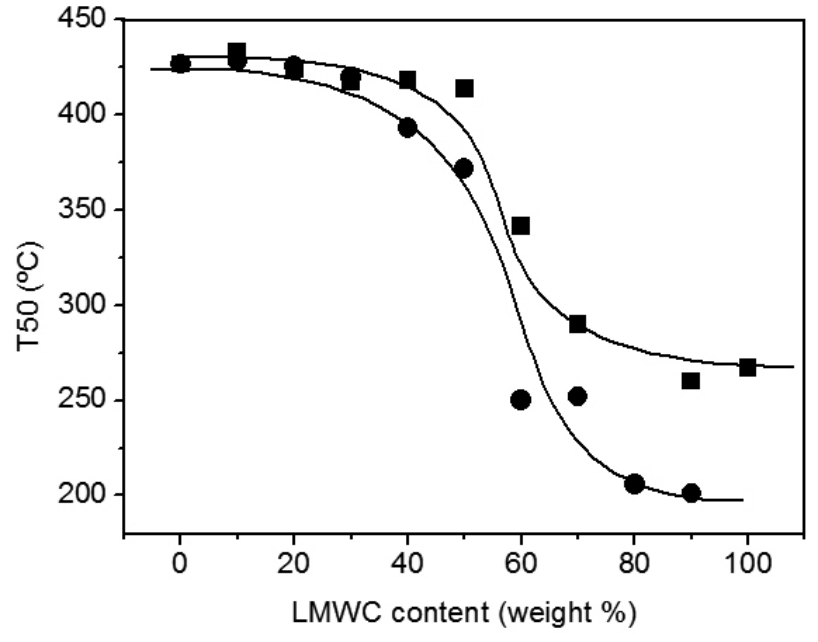

Figure 7. $\mathrm{T}_{50}$ variation with composition for blends $\mathrm{C}(\boldsymbol{\square})$ and $\mathrm{D}(\boldsymbol{)})$.

From the thermal decomposition profiles like those collected in Figure 6, $\mathrm{T}_{50}$ values were obtained and used as comparison criteria. At this temperature, usually used as thermal stability criterion, 50 weight $\%$ has been decomposed as a consequence of the applied heat. A fall of $T_{50}$ with the increase of LMWC content (see Figure 7), with intermediate values between the pure components, can be observed to blends $\mathrm{C}$ and $\mathrm{D}$. This behavior has been obtained for similar systems previously studied by the authors ${ }^{26-28}$ and can be interpreted in terms of a lower thermal stability degree as blends become richer in LMWC (44BP or 22BBP).

The effect of the blending process over morphological features of $\mathrm{C}$ and D systems was studied. For that, micrographs for the different blend compositions were obtained by Scanning Electron Microscopy (SEM). Figure 8 shows micrographs of selected compositions as representative examples.

In micrographs corresponding to the pure polymer it can be observed a homogeneous and uniform surface, which suffers morphological changes as the content of LMWC increases: grains and pores as irregularities and modifications associated to the addition of the crystalline compounds 44BP and 22BP.

Figure 6. Thermal decomposition profiles of blend D.
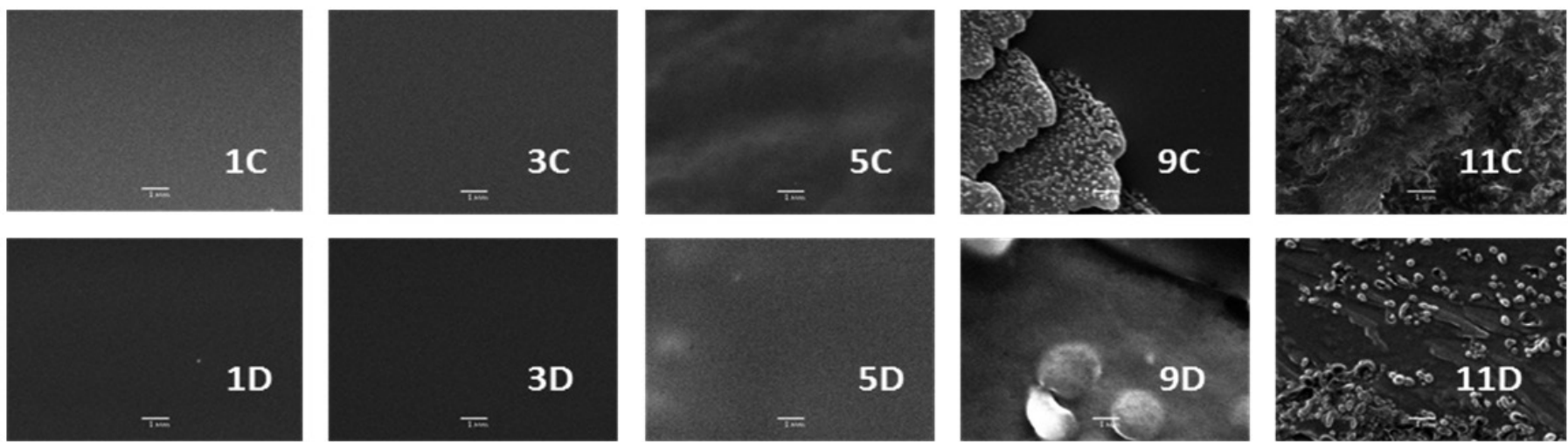

Figure 8. SEM micrographs for blends C (compositions 1C, 3C, 5C, 9C, and 11C) and D (compositions 1D, 3D, 5D, 9D and 11D). 
Blend C (PVP/44BP) show surface alteration from composition 5C (40\% 44BP), being so evident from composition $6 \mathrm{C}(50 \% 44 \mathrm{BP})$ up to the $10 \mathrm{C}$ one ( $90 \% 44 \mathrm{BP}$ ) due to the formation of granules and orifices typical of 44BP. In the case of blend D (22BP/PVP), structures associated to 22BP were observed only from composition $6 \mathrm{D}(50 \% 22 \mathrm{BP})$, being evident just in the sample $8 \mathrm{D}$ (70 \% 22BP). These results suggest a higher intermolecular interaction level between the components of blend $\mathrm{C}$, corroborating the behavior detected by DSC.

\section{CONCLUSIONS}

A decreasing in the glass transition temperature $(\mathrm{Tg})$ was detected as the content of LMWC increases (plasticizing effect). This behavior shows the bigger mobility acquired by the segments of the polymer chains when the molecules of 44BP and 22BP are located between them.

The effect of the blend process over the fusion of 44BP and 22BP was observed. Heat of fusion $(\Delta \mathrm{Hf})$ show a trend to the decreasing as the blend is richer in PVP, which can be attributed to the decreasing of the crystallinity degree of LMWCs in the blends.

Melting temperature $(\mathrm{Tm})$ of blend $\mathrm{C}$ decreases as the blend becomes richer in the polymer component, while $\mathrm{Tm}$ for blend $\mathrm{D}$ remains practically constant.

Interactions by means of hydrogen bonding among the components were detected. The infrared absorption band corresponding to the stretching of the PVP's carbonyl group was studied, which suffers an evident shifting toward lower wave numbers.

Thermal decomposition profiles for blends $\mathrm{C}$ and $\mathrm{D}$ were obtained by Thermogravimetrical Analysis. From them, the temperature intervals used in the calorimetric study were determined and a decreasing trend for the thermal stability is observed as the system is richer in LMWC.

Images obtained by scanning electron microscopy (SEM) demonstrate a change in the morphology of the blends. Typical structures associated with the incorporation of the LMWCs to the polymer component were observed. SEM results agree with the ones obtained by both DSC and FTIR.

\section{REFERENCES}

1. M. Rocha, Rev. Plást. Mod. 440, 149 (1993).

2. A. Taha, M. Magida, E. Shehata, J. Appl. Polym. Sci. 126, 1822 (2012).

3. J. He, F. Liu, Y. Luo, D. Jia, J. Appl. Polym. Sci. 126, 1527 (2012).

4. L. M. Robeson, W. F. Hale, C. N. Merrian, Macromolecules 14, 1644 (1981).

5. J. Y. Lee, P. C. Painter, M. M. Coleman, Macromolecules 21, 346 (1988).
6. D. J. T. Hill, A. K. Whittaker, K. W. Wong, Macromolecules 32, 5285 (1999).

7. T. Abou-Aiad, K. Abd-El-Nour, I. Hakim, M. Elsabee, Polymer 47, 379 (2006).

8. G. Stoclet, R. Seguela, J. M. Lefebvre, Polymer 52, 1417 (2011).

9. M. Urzúa, L. Gargallo, D. Radic', J. Appl. Polym. Sci. 84, 1245 (2002).

10. L. Ting Lee, E. Woo, J. Polym. Sci. Polym. Phys. 44, 1339 (2006).

11. C. S. Chang, E. Woo, J. H. Lin, Macromol. Chem. Phys. 207, 1404 (2006).

12. W. C. Lai, W. B. Liau, T. T. Lin, Polymer 45, 3073 (2004).

13. G. Makysh, L. Bimendina, S. Kudaibergenov, Polymer 43, 4349 (2002).

14. J. Areizaga, M. Milagros Cortázar, J. Elorza, J. Iruin, "Polímeros", Síntesis S. A., Madrid, España, cap. 12 (2002).

15. R. Kirk, D. Othmer, "Encyclopedia of Chemical Technology", John Wiley \& Sons, $4^{\text {a }}$ Edición, vol 3, pág. 435 (1991).

16. R. Kirk, D. Othmer, "Encyclopedia of Chemical Technology", John

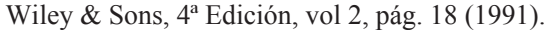

17. X. Wang, Y. Zhuang, L. Dong, J. Appl. Polym. Sci. 126, 1876 (2012).

18. G. Ovejero, M. Romero, E. Diez, I. Díaz, Eur. Polym. J. 46, 2261 (2010).

19. J. Liu, N. Hameed, Q. Guo, Eur. Polym. J. 46, 2290 (2010).

20. K. Pielichowska, S. Glowinkowski, J. Lekki, D. Binias, K. Pielichowski, J. Jenczyk, Eur. Polym. J. 44, 3344 (2008).

21. I. Krupa, G. Miková, A. Luyt, Eur. Polym. J. 43, 4695 (2007).

22. S. Bajpai, M. Bhowmik, J. Macromol. Sci. Pure Appl. Chem. 48, 108 (2011).

23. Z. Qiu, S. Fujinami, M. Komura, K. Nakajima, T. Ikehara, T. Nishi, Polymer 45, 4515 (2004)

24. B. Liu, W. Zhang, S. Zheng, Q. Guo, J. Polym. Sci. Polym. Phys. 44, 1618 (2006).

25. M. Rodríguez-Castro, L. Cesteros, I. Katime, S. Nuño-Donlucas, $J$. Polym. Sci. Polym. Phys. 44, 2404 (2006)

26. N. Gatica, N. Alvarado, D. Sepúlveda, J. Chil. Chem. Soc. 51, 945 (2006).

27. N. Gatica, N. Alvarado, J. Chil. Chem. Soc. 54, 317 (2009) and references therein.

28. N. Gatica, O. Monares, J. Chil. Chem. Soc. 55, 399 (2010).

29. H. Folttmann, A. Quadir, Drug Delivery Technology 8, 22 (2008).

30. D. Radic', A. Opazo, G. Vildósola, L. Gargallo, Polym. Int. 31, 175 (1993)

31. Y. He, N. Asakwa, Y. Inoue, J. Polym. Sci. Polym. Phys, 38, 2891 (2000).

32. Y. He, N. Asakawa, Y. Inoue, Macromol. Chem. Phys, 202, 1035 (2001).

33. J. Li, Y. He, Y. Inoue, J. Polym. Sci. Polym. Phys, 39, 2108 (2001). 